\section{Pretherapeutic evaluation of buried bumper syndrome by endoscopic ultrasonography}
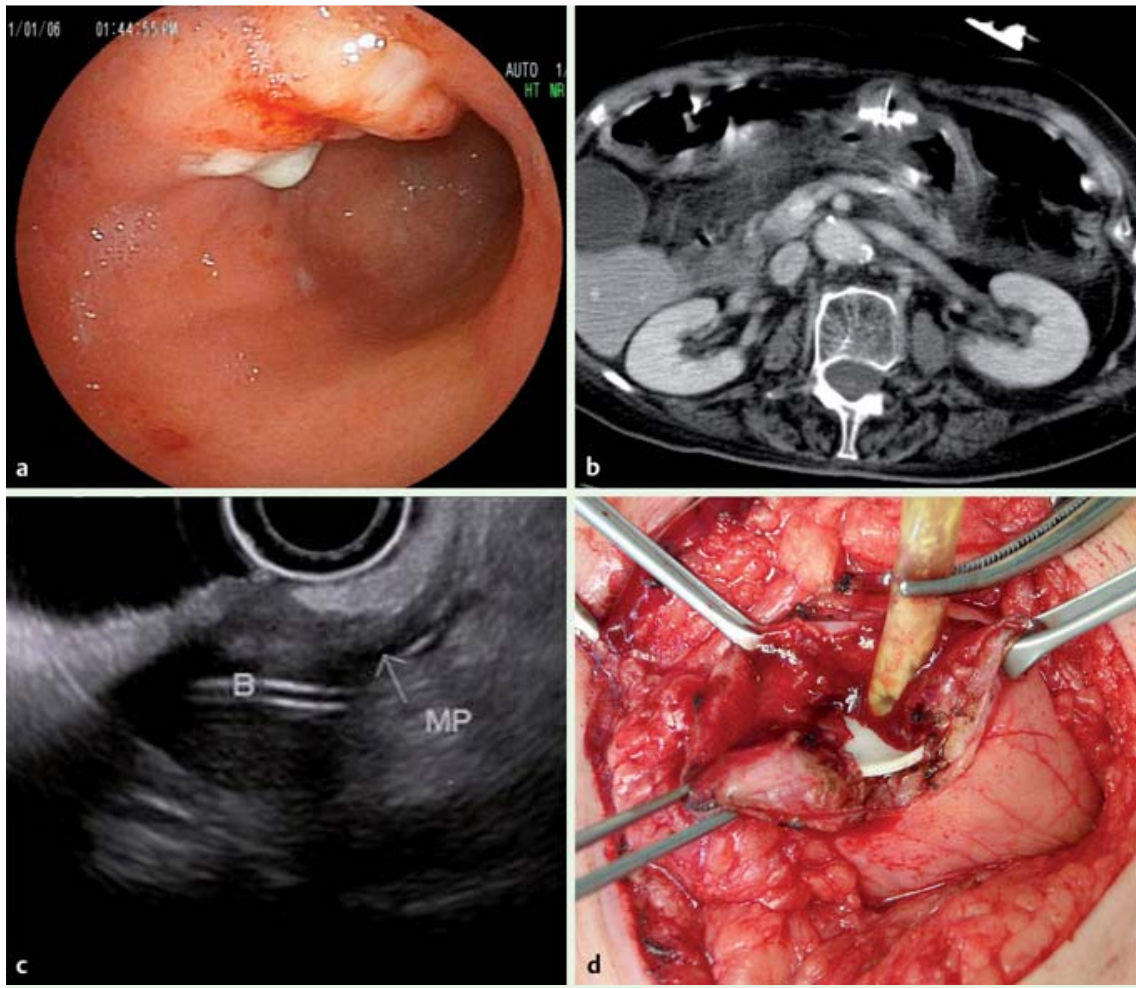

Fig. 1 a Esophagogastroduodenoscopy shows no internal bumper of a percutaneous endoscopic gastrostomy (PEG) tube in the gastric lumen, whereas a submucosal tumor-like lesion with a dimple and pus is seen in the anterior wall of the stomach where the internal bumper is supposed to be. $\mathbf{b} C \mathrm{C}$ shows that the internal bumper of the PEG tube seems to be within the gastric wall. $c$ Endoscopic ultrasonography demonstrates that the internal bumper of the PEG tube is located outside the gastric wall. $\mathbf{d}$ The finding at operation, showing that the internal bumper of the PEG tube is in an extramural location.

Buried bumper syndrome is one of the major complications of percutaneous endoscopic gastrostomy (PEG). Once it occurs, either endoscopic or surgical treatment is performed to remove the PEG tube [1 -5]. Although the endoscopic approach is less invasive, it carries the risk of perforation, depending on the location of the internal bumper $[3,5]$. We show the clinical usefulness of endoscopic ultrasonography (EUS) for selecting safe and appropriate treatment of buried bumper syndrome.

The patient was a 73-year-old woman with dementia who required tube feeding. She had undergone PEG at the age of 68. No complications were associated with the PEG tube until December 2011, when the nurses noticed an obstruction in the tube. Esophagogastroduodenoscopy showed no internal bumper of the PEG tube but a submucosal tumor-like lesion with a dimple in the anterior wall of the stomach where the internal bumper was supposed to be ( $\nabla$ Fig. 1 a). CT could not give us an accurate location of the internal bumper so that we could decide whether intramural or extramural treatment was appropriate ( Fig.1b). EUS (EG530UR2; Fujifilm, Tokyo, Japan) demonstrated that the 3.5-cm-diameter low-density area that suggested abscess formation was located not only in the gastric wall, but also outside of the gastric wall. Importantly, a portion of the internal bumper of the PEG tube was detected outside the gastric wall ( Fig.1c). Thus, pretherapeutic EUS was able to accurately diagnose the location of the buried internal bumper of the PEG tube. In accordance with the EUS results, surgical treatment was performed for removal of the PEG tube. Intraoperative findings confirmed that the internal bumper of the PEG tube was in an extramural location ( Fig. $1 \mathrm{~d}$ ). We believe that pretherapeutic EUS is a useful test for evaluation of buried bumper syndrome and for determining the appropriate therapeutic approach to it.

\section{Endoscopy_UCTN_Code_TTT_1AO_2AK}

Competing interests: None

\section{Y. Tanaka', K. Akahoshi' ${ }^{1}$, Y. Moto- mura $^{1}$, T. Osoegawa ${ }^{1}$, T. Yukaya ${ }^{2}$, E. Ihara ${ }^{3}$, R. Iwao', K. Komori ${ }^{1}$, N. Nakama', S. Itaba ${ }^{1}$, M. Kubokawa ${ }^{1}$, T. Hisano ${ }^{1}$, K. Nakamura ${ }^{3}$}

${ }^{1}$ Department of Gastroenterology, Aso lizuka Hospital, lizuka, Japan 2 Department of Surgery, Aso lizuka Hospital, lizuka, Japan

3 Department of Medicine and Bioregulatory Science, Graduate School of Medical Sciences, Kyushu University, Fukuoka, Japan

\section{References}

1 Rieder B, Pfeiffer A. Treatment of the buried bumper syndrome using a Savary dilator. Endoscopy 2007; 39: E115

2 Binnebösel M, Klink CD, Otto J et al. A safe and simple method for removal and replacement of percutaneous endoscopic gastrostomy tube after "buried bumper syndrome". Endoscopy 2010; 42: E17-18

3 Leung E, Chung A, Hamouda A et al. A new endoscopic technique for the buried bumper syndrome. Surg Endosc 2007; 21: $1671-1673$

4 Ma MM, Semlacher EA, Fedorak RN et al. The buried gastrostomy bumper syndrome: prevention and endoscopic approaches to removal. Gastrointest Endosc 1995; 41: $505-$ 508

$5 \mathrm{Vu} C \mathrm{CK}$. Buried bumper syndrome: old problem, new tricks. J Gastroenterol Hepatol 2002; 17: $1125-1128$

\section{Bibliography}

Dol http://dx.doi.org/

10.1055/s-0031-1291715

Endoscopy 2012; 44: E162

(c) Georg Thieme Verlag KG

Stuttgart · New York

ISSN 0013-726X

\section{Corresponding author}

\section{K. Akahoshi, MD, PhD}

Department of Gastroenterology

Aso lizuka Hospital

3-83 Yoshio

lizuka 820-8505

Japan

Fax: +81-948-298747

kakahoshi2@aol.com 